\title{
The Sustainable Design of City Hanging Gardens
}

\author{
Guoling Qiao, a \\ ${ }^{1}$ Department of Art and Design, College of Textile and Garment, Guangzhou University, Guangzhou, \\ Guangdong, 510165, China \\ agzhqiaoguoling@126.com
}

\begin{abstract}
Keywords: Hanging Garden, Sustainable Design, Tree Cube, Urban Diseases
\end{abstract}
Abstract. Recent years, with the speed-up of urbanization, especially great population's moving into the city, urban diseases like city water-logging, waste processing, sewage discharging, traffic congestion, air pollution and city infrastructure backwardness become even serious. Besides, traditional city humanities, history, ecology, commercial mode and living environment are difficult to develop. Except expanding new cities and satellite cities, how to establish a sustainable outlook becomes a hot topic. In this paper, from the perspective of sustainable development of city hanging gardens, taking the Tree Cube in Changzhou and the K11 art mall in Shanghai as examples, we discuss the positive role played by the hanging gardens in solving the urban diseases; analyze the current problems, and striving to seek the sustainable development of urban living environment.

\section{Introduction}

The hanging garden, also called the roof garden, generally refers to the garden greening system out of the ground. In a narrow sense, the hanging garden means the garden built on the top of the building, while in a broad sense, it refers to the garden built on the top of the building, on the roof, balcony, walls and etc.. Unlike the garden on the ground, the hanging gardens can be affected by a lot of factors, such as the bearing capacity of the building, the waterproofing and the drainage, the soil cushion and the wind. The design and the construction of the hanging garden is an integrated and specialized field for making the sustainable urban ecological development. It also plays as a basic platform for improving the living environment of the urban citizens[1]. This paper aims to explore a way to reduce the emission of the building by the ecosystem of the hanging gardens, thus to improve the connection between natural environment and city space, promoting a comprehensive development for both construction of the hanging gardens and the economic benefits[2].

\section{Urban Development and the City Hanging Gardens}

Urban Constructions Provide Broad Space for Hanging Gardens Building. The urbanization of China makes more and more population concentrated in important cites, especially in metropolises. The expansion of the city makes the space getting smaller, and the environment becoming worse. The existing city infrastructure cannot meet the needs of the growing population, which results in the contradiction between the urban construction and the development[3]. At the same time, we should notice that the development of the city offers more and more possible platforms for the construction of the hanging gardens.

The History of the Hanging Gardens and Its Inspiration. The hanging garden derived from the ancient Babylon. Built in the sixth century BC, the Babylon hanging garden is regarded as one of the Seven Wonders of the World. The archaeological of the site shows that it was built on the arch columns, like floating in the air, so it was called 'Hanging Garden'. The Babylon hanging garden was built to relief the nostalgia of the king. Walking in it, you can overlook the city's natural environment, observe the life of the citizens, and learn the trade activity on the commercial street. In contrast, in the current greening system in China, the garden, commercial street and the urban landscape are isolated.

The Future of the Hanging Garden. The hanging gardens expand more space for urbanization, and its ecological characteristics like eco-friendly, improving micro-climate, and sustainable 
development is more attractive[4]. The building roof occupies a great proportion in the projection area of urban construction, especially in the cities with high density. Considering the high price of the urban land, it is a good choice to build hanging gardens. The demand of urban people, the roof space of the building, the commercial development and other factors will all play positive roles in the development of the city's hanging gardens.

\section{The Ecological Innovation of the Tree Cube in Changzhou}

The Vertical Greening Structure Changes the Opposition between the Building and the Land. Located in the Wujin district of Changzhou city in Jiangsu province, the Tree Cube is a building of scientific research office studying roof greening which is the first 'unpowered vertical planting building with the ability to store energy'. It was the only project to win the platinum award on the Nanjing World Green Roof Congress, 2013. Covering 700 sqm, the Tree Cube create 2300 sqm green area, achieving the goal of 'three acres of green land on an acre of the land', generates new ecological space while minimizing the damage to the land. With the grafting of the building structure, construct the hanging garden can give new ecological meaning to the land.

The Tree Cube is a Case of Ecological Reconstruction Based on Building Structure. Make Full Use of Architectural Space for Greening: In the Tree Cube, you can find roof greening, balcony greening, wall greening and indoor garden everywhere on each one of the totally six floors of the Tree Cube. According to the features of the space, it builds stereo layout like the forest. As shown in Fig. 1, by building modern ecological micro farm, eco-garden, eco-orchard, eco-kitchen, dining ecology, eco-toilet, eco oxygen bar, and artificial roof wetland on the top of the building, it achieves micro-circulation and forms micro eco-chain.

The Pursuit of Natural, Livable and Beauty is the Ultimate Goal of Building Ecological Reconstruction: The most distinctive difference between natural and artificial ecology is people's attitude toward it. The negative attitude indulges the randomness of the nature, which forms the original ecological structure. While the positive attitude generates the artificial nature, which is controllable, offering comfortable living environment and meets people aesthetic needs. The Tree Cube vertical greening is a reconstruction based on the building structure, which shows positive attitude of people to nature transformation.

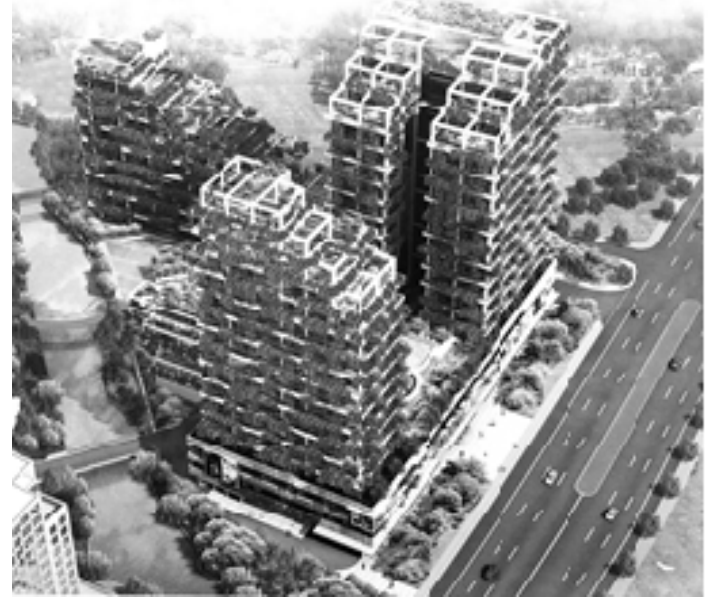

Fig. 1 The overlook view and local floor plan picture of the Tree Cube, Changzhou

The Ecological Reconstruction on Building Structure is based on the Ecological Technology. Take the water circulation and the energy saving as example, as shown in Fig.2, the Tree Cube's water collection system is set in water storage layer at the bottom of the hanging garden, which can collect $95 \% \sim 100 \%$ of the rainwater. Besides, it realizes unpowered automatic watering, saving $80 \%$ of the water. What's more, by technical processing, the sewage and the kitchen waste can be transformed into organic fertilizer to be used in greening of the hanging garden. After the implementation of the unpowered purification by constructed wetlands, the water quality can 
eventually reach 3-level standard, and waste water and sewage can be totally collected, which releases the pressure on the urban infrastructure caused by the building emission.

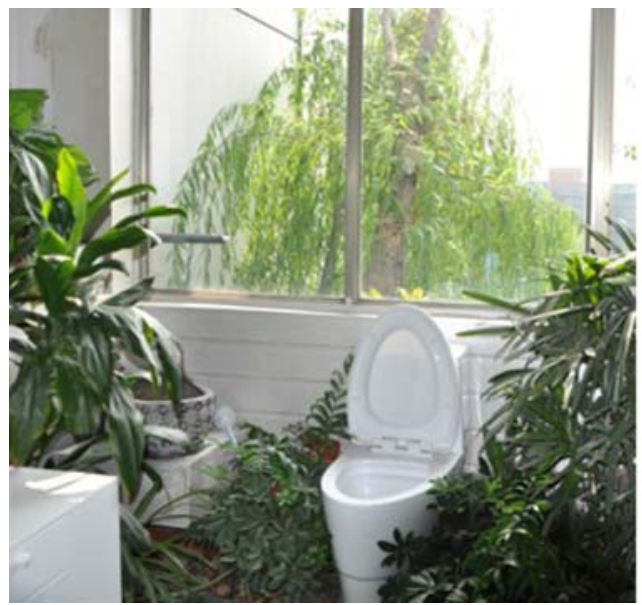

Fig. 2 The water cycling system of the Tree Cube, Changzhou

The Hanging Garden's Effective Constraint on Building Emissions. To achieve sustainable eco-construction, the building should uses local materials, and should not bring new burdens on the environment and municipal operation. Besides, it should make a positive contribution to improving the local environment. To achieve the hanging garden's effective constraint on building emissions, we should take the hanging garden into consideration before the construction planning and design, rather than considering the roof greening after the building finished, because the loss caused by renovation will offset some of the economic interests of the landscape. Only when the new buildings realize self-circulation like the Tree Cube can the hanging gardens fully play the role of constraints on the building.

\section{Shanghai K11 Art Mall and Its Reference Significance.}

Located in the heart of Shanghai's central shopping street, Huaihai Road, the gross area of K11 art mall Shanghai reaches over 9, $100 \mathrm{sqm}$. The podium of the landmark New World Tower, an icon of the 1990's commercial renaissance of Shanghai, was transformed into a cultural and commercial project integrating shopping, art, culture and ecology as a whole.

A Bold Attempt of the K11 Art Mall's Design. The inner courtyard featuring the 33 meters high waterfall, the tallest outdoor waterfall in Asia, runs in an automatic inductor system where the water consumption is optimized depending on the climactic conditions and also features an extensive areas of over 2, 000 sqm of living vertical gardens which collect rainwater that is then re-used in other areas of the project including the buildings cooling systems. A large area of vertical green wall reduces the light pollution of the building. Large-area's usage of glass walls in modern constructions causes high energy consumption and serious light pollution, especially the sunlight reflection between glass cladding of tall buildings. The vertical greening on the building walls can weaken the direct reflection, and thus reduce the light pollution.

Design of the K11's Hanging Garden. The circulation design of the K11 adapted the idea of Imaginary Journey. The whole journey contains six ground floor and three basement floor with the design of the hanging garden in each node of the journey. The Imaginary Journey separates the customers by different functions, form the visual characteristics and interweave elements of life with natural materials, and art exhibition area with public space, which allows people to experience the originality while touring. There is a special urban farming on the third floor with nearly 300 sqm's indoor planting area which allows customers to experience ecological interactive. On the six floor, there is a luxuriant urban oasis, an open-air viewing spot hard to find in cities. Besides the visual enjoyment, the hanging garden can also reduce dust-fall pollution by the sorption of leaves on dust, 
effectively purifying the air, improving the air quality in the city especially the haze problem. At the same time, it can effectively reduce the greenhouse effect and the building energy consumption.

\section{The Dilemma of Hanging Garden's Sustainable Development}

Due to the high cost of hanging garden's greening and the lack of compulsory terms, most developers are unwilling to build the roof gardens. For now, it is short-sighted because the roof greening has a close relationship with new business value. To realize the sustainable development of the hanging garden, we need to explore this potential of value.

Sustainable Development of the Hanging Gardens and Urban Space. Developing the hanging garden can attract attention and bring extra business value. Like the Redstar Macalline in Shanghai, by building roof garden on the top, constructing children recreational facilities and café, it can create extra value in addition to its market operation. The Namba mall in Osaka has an eight floors' hanging garden across several blocks. The designer made full use of the space to build the woods, rock garden, cliffs, valleys, grasslands, streams, waterfalls, ponds, vegetable fields and etc.. On the most densely populated street in Osaka, this hanging garden redefines the urban space.

The Comprehensive Development of the Ecological Value of the Hanging Garden. Apart from the influence the economic value has on sustainable development, others like charity, education, and ecology and environment protection are assignable to develop. For example, if the hanging garden of the campus building can be divided into different planting area, and set cards to learn the knowledge of the plant, the botany courses will become much more vivid. Open up part of the plantation can encourage the students to enjoy laboring. Another example is the construction of the hanging garden on the top of the office building, which expands the outdoor space for business people, and it's convenient for them to access to the natural leisure space.

\section{Summary}

The current construction of China's hanging garden is still at the primary stage. As the city development troubled by various urban diseases, the ecological effects generated by the hanging garden become increasingly prominent. To build mature hanging gardens in the future, we need a deep study to integrate eco-efficiency with economic benefits, and coordinate bill establishment with proactive behaviors, to achieve the sustainable development of the hanging gardens.

\section{References}

[1] J. H. Han, J. G. Li, Q. Wang. Indoor Pollution Sources Detection Technology and Equipment Development, Construction Technology, Vol. 18(2013), p.39-41

[2] Q. He. City Planning Principle. China Architecture Industry Press, Beijing, China (2001)

[3] L. X. Cao. The Development Trend of Green Building Design, China New Technology And New Products, Vol. (2014), p.172-175

[4] F. Li. Important Role of Green Building to the Construction of Low Carbon City, Chinese Construction, Vol. 18 (2015), p.70-73 